\title{
The Oxford Shoulder Instability Score; validation in Dutch and first-time assessment of its smallest detectable change
}

\author{
Just A. van der Linde ${ }^{1 *}$, Derk A. van Kampen ${ }^{2}$, Loes W. A. H. van Beers ${ }^{1}$, Derek F. P. van Deurzen ${ }^{1}$, \\ Caroline B. Terwee ${ }^{3}$ and W. Jaap Willems ${ }^{4}$
}

\begin{abstract}
Background: The Oxford Shoulder Instability Score (OSIS) is a short, self-reported outcome measurement for patients with shoulder instability.

In this study, the OSIS was validated in Dutch by testing the internal consistency, reliability, measurement error, validity and the floor and ceiling effects, and its smallest detectable change (SDC) was calculated.

Methods: A total of 138 patients were included. Internal consistency was calculated with Cronbach's a. Reliability (test-retest) was calculated with the intraclass correlation coefficient (ICC). The measurement error was calculated (SEM), and the SDC was estimated in a subgroup of 99 patients that completed the re-test after a mean of 13 days (5-30 days). Construct validity was evaluated by comparing the OSIS with the Western Ontario Shoulder Instability index (WOSI), the Simple Shoulder Test (SST), the Oxford Shoulder Score (OSS), the Disability of the Arm, Shoulder, and Hand assessment (DASH), and the Short Form-36 (SF-36).
\end{abstract}

Results: Internal consistency was good, with a Cronbach's a of 0.88 . The reliability was excellent, with an ICC of 0.87 . The SEM was 3.3 and the SDC was 9 points (on a scale of $0-48$ ). Regarding the construct validity, $80 \%$ of the results were in accordance with the hypotheses, including a high correlation (0.82) with the WOSI. No floor or ceiling effects were found.

Conclusions: The Dutch version of the OSIS showed good reliability and validity in a cohort of patients with shoulder instability.

Keywords: Validation, Oxford, Shoulder, Instability, Score, Dutch

\section{Background}

Shoulder instability is common in orthopedic practice; it generally affects young, active patients [1-3].

Research and evaluation of therapies for shoulder instability should focus both on objectively verifiable outcomes, such as the range of motion and re-dislocations, and on subjective functioning. A variety of patient-reported outcome measures (PROM) exist, some of which are specifically designed to reflect the patient's subjective assessment of function. They enable the practitioner to detect functional changes in a standardized format. Because

\footnotetext{
* Correspondence: javdlinde@gmail.com

${ }^{1}$ Department of Orthopedic Surgery and Traumatology, Onze Lieve Vrouwe Gasthuis, Postbus 95500, 1090 HM Amsterdam, The Netherlands

Full list of author information is available at the end of the article
}

patients and doctors do not always agree on functional outcome after therapeutic interventions [4], PROMs have become increasingly important in assessing patient health status [5]. They can focus on general health; a physical domain or body part, such as the shoulder; or a specific condition or disease, such as instability [5-7].

The Oxford Shoulder Instability Score (OSIS) is a comprehensive questionnaire including 12 questions to assess shoulder instability. With a Cronbach's $\alpha$ of 0.92 , a Pearson correlation coefficient of 0.97 and measurement error of 5.7 , the OSIS has proven to be valid and reliable, making it clinically important in patients with shoulder instability [8]. The OSIS was proven to be a useful outcome measure in several clinical studies [9-11], but 
it has not been translated and validated in languages other than English.

Translation and validation of internationally used PROMs will lead to culturally equivalent instruments and allow direct comparisons of national and international study results [12-14]. The aim of this study was to translate and validate the OSIS for the Dutch population and to evaluate its measurement properties according to the Consensusbased Standards for the selection of health Measurement Instruments (COSMIN) guidelines [15].

\section{Methods}

\section{Translation procedure}

After we obtained the official licence for the original English version, the OSIS was independently translated into Dutch by three native Dutch-speaking, medically educated translators. When they reached a consensus, a professional translator and a native English speaker (without a medical background) independently translated the version back into English; both were blinded to the first version and emphasized specifically on the linguistic aspects. Finally, the latter version was compared to the original text, composing a pre-final version. All items were agreed to be relevant for this patient population, and taken together, the items represented a comprehensive measurement of shoulder instability.

The pre-final version was checked for cross-cultural differences. It was subsequently completed by 13 patients with shoulder instability that were asked independently to assess the comprehensibility of all questions. These patients were not included in our final analysis.

\section{Patients and procedures}

To assess the reliability and validity of the OSIS in the Dutch population, 154 patients with shoulder instability were recruited. Institutional approval was obtained by the local ethics committee; Institutional Review Board (IRB): METC, OLVG Hospital, Amsterdam, The Netherlands. Written informed consent was obtained from all participants.

We planned to include at least 100 patients, which is considered excellent for assessing measurement properties $[15,16]$.

A total of 154 patients with shoulder instability were included; all were diagnosed by one of the doctors in the outpatient clinic or the emergency department.

Patients were eligible to participate when they were 16 years or older and had been diagnosed with shoulder instability, based on their history and clinical examination. All patients were included on the ER or outpatient department of a hospital in Amsterdam. Exclusion criteria were an inability to master the Dutch language, a fracture in the glenoid, or a fracture in the humeral head. Hill-Sachs lesions and bony Bankart lesions were included. Tourists and temporary inhabitants of Amsterdam that were followed up in another clinic were also excluded, to avoid patient burden as a result of double follow-up.

All patients were assigned a study number and received either a web-based questionnaire, or alternatively, an identical paper questionnaire to complete at home. The order of administration was fixed. The web-based version required answers to all questions prior to submission. Missing values in paper submissions were completed in an interview by telephone.

Patients were asked to complete the questionnaire twice, without intervention. Both times, the questionnaire was either web-based or on paper. The repeated questionnaire was completed after a maximum interval of 5 to 30 days; this interval was considered long enough to forget prior answers, and short enough to assume an unchanged shoulder condition $[17,18]$.

\section{Oxford Shoulder Instability Score}

The OSIS is a disease-specific PROM that was developed by Dawson et al. in 1999 in the UK for assessing the outcome of treatment for shoulder instability [8].

This 12-item questionnaire contained five response categories for each question. In the original scoring system, answers were scored from 1 to 5 points and summarized to a total score that ranged from 12 (least impaired) to 60 (most impaired). The scoring system was revised in 2009 , in accordance with the revised scoring for the Oxford Shoulder Score (OSS), which originated in the same institute [19]. In the revised scoring system, answers were scored from 0 to 4 , and the score was reversed; thus, the total score ranged from 0 (most impaired) to 48 (least impaired). We presented the results in terms of the new scoring system.

The OSIS was originally validated in 92 patients with shoulder instability that against the Rowe and Constant scores, with correlations of 0.51 and 0.56 , respectively. The internal consistency (Cronbach's $\alpha$ ) was 0.92. The reliability was 0.97 , calculated with a Pearson correlation coefficient. The measurement error was 5.7 points, calculated with the Bland and Altman method. No intraclass correlation coefficient (ICC) was calculated [8]. To date, no cross-cultural validation has been conducted.

\section{Validation instruments}

The following instruments were solely used to assess the construct validity of the OSIS. No other data is used from these additional questionnaires. All instruments have been validated in Dutch, with good to excellent reliability and internal consistency [17, 20-23].

\section{Western Ontario Shoulder Instability index (WOSI)}

The WOSI is a disease-specific PROM for assessing the outcome of treatment for shoulder instability [24, 25]. 
Responses to the 21-item questionnaire were summarized in a total score, ranging from 0 or $0 \%$ (no limitations) to 2100 or $100 \%$ (extreme limitations).

It has been validated in Italian, German, Swedish, Japanese and Dutch [20, 26-30]. The Dutch version was validated using the same dataset as was used for the OSIS validation.

\section{Simple Shoulder Test (SST)}

The SST is a body-part-specific PROM [31]. It was designed to measure functional limitations of patients with general shoulder complaints. A cumulative score is calculated based on 12 questions (yes/no) and ranges from 0 (poor) to 12 (excellent shoulder function). It was validated against the American Shoulder and Elbow Surgeons (ASES) survey with a correlation of 0.81 [31].

\section{Oxford Shoulder Score (OSS)}

The OSS is a body-part-specific PROM. It was developed and validated for patients with general shoulder complaints [32]. Responses to the 12-item questionnaire were summarized to a total score that ranged from 12 (least impaired) to 60 (most impaired). This scoring system was revised in 2009 [19]. Currently, answers are scored from 0 to 4 , and the summary is reversed; thus, the total score ranges from 0 (most impaired) to 48 (least impaired).

The OSS was originally validated against the Constant shoulder score and the SF-36 subscales [32]. Since that validation, it has been validated in Danish, Korean, Turkish, Italian, German, and Dutch [22, 33-37].

\section{Disability of the Arm, Shoulder, and Hand (DASH) assessment} The DASH assessment is a body-part-specific PROM designed [38] to measure physical function and symptoms in patients with musculoskeletal disorders from any condition in any joint in the upper extremity.

Responses to the 30-item questionnaire are used to calculate the total score by averaging the item scores, subtracting 1 , and multiplying the result by 25 . The resulting score ranged from 0 (no disability) to 100 (extreme disability).

The DASH was shown to be reliable, valid, and responsive for patients with shoulder disabilities $[39,40]$.

\section{Short form 36 Health Survey, version 1 (SF-36)}

The SF-36 is a general health PROM that includes 36 questions for assessing the general health of patients with all kinds of disorders. It is the most widely used PROM for assessing general health [41]. It includes eight domains: physical function, social function, role limitations caused by physical problems (role physical), role limitations caused by emotional problems (role emotional), general mental health, vitality, bodily pain and perception of general health. Each domain has a total score of 0 (extremely poor) to 100 points (no complaint) [42].

The SF-36 was translated and validated in a Dutch general population, with a mean alpha coefficient across all scales and samples of 0.84 . Previous studies have also validated the SF-36 specifically for shoulder complaints [43, 44].

\section{Assessments of measurement properties Internal consistency and factor analysis}

Internal consistency tells you to what extend different items within one questionnaire measure the same construct of interest (e.g. shoulder instability). Ideally, this score is high, indicating that all items measure the same construct. The internal consistency of the OSIS was assessed by calculating Cronbach's $\alpha$. For acceptable internal consistency, the Cronbach's $\alpha$ should preferably be $\geq 0.7$ [43].

Internal consistency can also be addressed using confirmatory factor analysis. See Additional file 1: Appendix 1.

\section{Measurement error}

Measurement error is the systematic, random error in the construct, which cannot be attributed to true changes in the patient's condition [6]. When a score changes within the range of measurement error, it is not clear whether the change is a true effect of therapy or whether it should be attributed to measurement error.

Measurement error can be expressed as the standard deviation of repeated measurements in a single patient, referred to as the standard error of measurement (SEM). The SEM was calculated from the square root of the variance between the measurements and the error variance of the ICC. Subsequently, the SEM can be transformed into the smallest detectable change ( $\mathrm{SDC}=1.96 * \sqrt{2} * \mathrm{SEM})$. The SDC represents the minimal change that a patient must show to ensure that the observed change is real, and not a measurement error [45]. The SDC is thus calculated; it is not derived from clinical observations following treatment.

\section{Reliability}

Since each instrument has a degree of uncertainty due to measurement error, reliability is defined as the degree to which the measurement is free from measurement error [6]. The reliability refers to the proportion of the total variance in the measurements that can be attributed to true differences between patients. Reliability was assessed by calculating the ICC, which was calculated with a two-way, mixed-effects model for absolute agreement. The mixed-effect model is used because a 'fixed' value (all questions remained unchanged during the whole cohort) is compared to a 'random' value (a cohort of patients was selected from all patients with shoulder instability). Scores $\geq 0.70$ are considered adequate [45]. 


\section{Construct validity}

Construct validity reflects whether the instrument measures what it was designed to measure. In case of shoulder instability, do questions actually measure the typical complaints following shoulder instability (e.g. How much pain do you experience in your shoulder with overhead activities?)? In the absence of a gold standard for comparison, hypotheses are formulated that state the expected correlation between the investigated instrument and similar PROMs. In this study, the condition-specific OSIS was compared with the condition-specific WOSI (instability) and with the body-part-specific SST, OSS and DASH (shoulder). Finally, it was compared with several subscales of the original version of the SF-36 for measuring general health status. Pre-determined a priori hypotheses are stated in Table 1. These six hypotheses lead to a total of 42 correlations (or comparisons between correlations). The hypotheses were based on clinical experience, knowledge about several PROMs, and a consensus among the study investigators.

The highest correlation $(\geq 0.7)$ was expected between the two disease-specific PROMs (OSIS and WOSI). High correlations $(\geq 0.6)$ were expected between similar bodypart-specific PROMs (OSIS and SST, OSS, and DASH). These correlation coefficients were expected to be at least 0.1 higher than the correlations between the OSIS and the more general subscales of the SF-36. Finally, because the OSIS predominantly measured physical function, we expected the correlation between the OSIS and the SF-36 physical function to be at least 0.1 higher than the correlations between the OSIS and the other SF-36 subscales.

Construct validity was considered good when at least $75 \%$ of the results (correlations) were in accordance with our hypotheses [46].

\section{Floor and ceiling effects}

Floor and ceiling effects occur when more than $15 \%$ of patients achieve the lowest or highest possible score, respectively [47]. Moreover, when a patient scores close

Table 1 Pre-determined hypotheses for testing the validity of the Dutch version of OSIS; expected correlations

\begin{tabular}{ll}
\hline & Expected correlations \\
\hline $\begin{array}{ll}\text { 1. OSIS and WOSI } \\
\text { 2. OSIS and SST }\end{array}$ & $\geq 0.7$ \\
3. OSIS and OSS & $\geq 0.6$ \\
4. OSIS and DASH & \\
5. Correlation between OSIS and body-part-specific PROMs (SST, OSS, \\
and DASH) should be at least 0.1 higher than that between OSIS and \\
the generic SF-36 subscales \\
6. Correlation between OSIS and SF-36 physical function scale should \\
be at least 0.1 higher than the correlations between OSIS and the other \\
SF-36 subscales
\end{tabular}

to one of the extremes at baseline, a real change (defined as the SDC) could cross that extreme. Patients that score within the SDC-range from one of the extremes can thus be regarded as being at either their floor or ceiling too.

\section{Statistical analyses}

Statistical analyses were performed with SPSS software, version 18.0.0 (SPSS, Gorinchem, The Netherlands).

\section{Results}

No major differences occurred between the OSIS translations into Dutch and back into English, no content- or linguistic-related difficulties were reported. The final version was considered free of cross-cultural inconsistencies; all questions are applicable to the Dutch population.

Figure 1 presents the selection of participating patients. One hundred and thirty-eight patients with shoulder instabilities completed the first questionnaire; 99 patients were eligible for the second questionnaire. The shoulder function, presented as the mean and SD scores of the WOSI, SST, OSS and DASH, did not differ significantly between the two measurements.

The demographic data and mean PROM scores are summarized in Table 2.

\section{Internal consistency and factor analysis}

For all 138 patients that completed the OSIS at baseline, the Cronbach's $\alpha$ was 0.88 , indicating good internal consistency.

\section{Reliability}

The mean time between the completion of the first and second questionnaires was 13 days (5-30). Table 3 presents the scores of the tests and re-tests and the ICC with a $95 \%$ confidence interval (ICC is $0.87(0.82-0.91)$. These results indicate excellent reliability.

\section{Measurement error}

The SEM was 3.3, which resulted in a SDC of 9.0 points, indicating that a patient has to show a change of 9.0 points to ensure the detection of a true change. This is $19 \%$ of the total range.

\section{Construct validity}

The observed correlation results are summarized in Table 4 . In total, $80 \%$ of the results were in accordance with our hypotheses. The hypotheses were confirmed for the correlation between the OSIS and the other instabilityspecific WOSI $(0.82 ; \geq 0.7$ expected) and the correlations between the OSIS and the shoulder-specific SST, OSS and DASH $(0.69,0.76$, and 0.79 , respectively; $\geq 0.6$ expected). The hypothesis was partly confirmed for the strength of the correlation between the OSIS and the SF-36 subscales. 


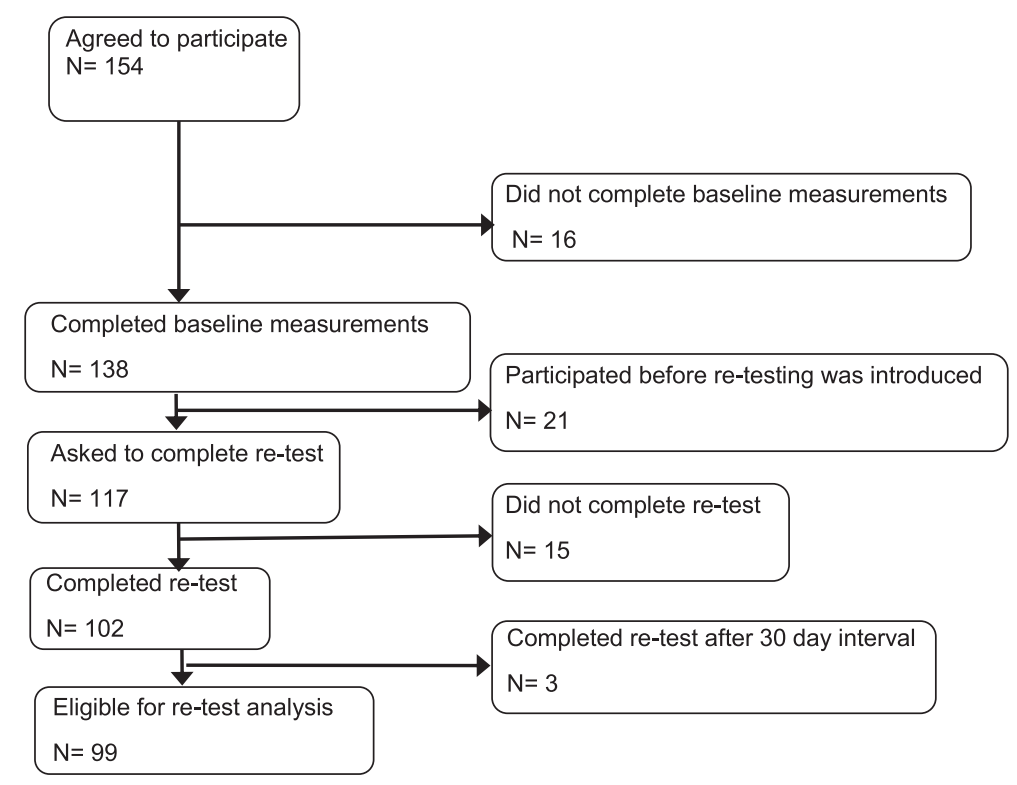

Fig. 1 Flowchart of selection of patients that participated in the study

Table 2 Demographic data of patients completing baseline and the reliability cohort

\begin{tabular}{|c|c|c|}
\hline & $\begin{array}{l}\text { Baseline assessment } \\
N(\%)\end{array}$ & $\begin{array}{l}\text { Reliability cohort } \\
N(\%)\end{array}$ \\
\hline Mean age, year (SD) & $32(12)$ & $32(14)$ \\
\hline Gender (male) & $98(71 \%)$ & $66(66 \%)$ \\
\hline \multicolumn{3}{|l|}{ Dislocated shoulder } \\
\hline Right & $72(53 \%)$ & $54(55 \%)$ \\
\hline Left & $59(43 \%)$ & $40(40 \%)$ \\
\hline Both & $6(4 \%)$ & $5(5 \%)$ \\
\hline Dominant side dislocated & $73(53 \%)$ & $53(54 \%)$ \\
\hline \multicolumn{3}{|l|}{$\begin{array}{l}\text { Time first dislocation to } \\
\text { completion OSIS }\end{array}$} \\
\hline$<1$ month & $8(6 \%)$ & $8(8 \%)$ \\
\hline $1-6$ months & $21(15 \%)$ & 17 (17 \%) \\
\hline$>6$ months -2 years & $40(29 \%)$ & $25(25 \%)$ \\
\hline$>2$ years & $67(49 \%)$ & $49(50 \%)$ \\
\hline $\begin{array}{l}\text { Sports-related traumatic } \\
\text { instability }\end{array}$ & $71(54 \%)$ & $47(47 \%)$ \\
\hline$(100-0)^{\mathrm{a}}$ & $46.0(22.3)$ & $45.7(24.2)^{b}$ \\
\hline$(0-12)^{a}$ & $8.8(3.1)$ & $8.8(3.2)^{b}$ \\
\hline$(48-0)^{a}$ & $23.7(7.8)$ & $22.8(8.3)^{\mathrm{b}}$ \\
\hline$(100-0)^{a}$ & $22.2(16.7)$ & $22.7(18.3)^{b}$ \\
\hline
\end{tabular}

${ }^{\text {a }}$ Ranges reflect most impaired to least impaired function ${ }^{\mathrm{b}}$ No significant change in shoulder function (WOSI, SST, OSS, DASH) was observed at re-test compared to the baseline assessment

\section{Floor and ceiling effects}

No patients scored minimum or maximum scores. At most, $12 \%$ of patients scored within the SDC-range for the lowest possible score. The results are presented in Table 5.

\section{Discussion}

There is a growing interest in PROMs for both clinical and research purposes to supplement clinical outcome measures. To our knowledge, this is the first study to validate the OSIS in a foreign language and the first to report the measurement error and evaluate floor and ceiling effects.

The results show a high internal consistency (Cronbach's $\alpha=0.88$ ); it was only slightly lower than that described in the original article (Cronbach's $\alpha=0.91$ at pre treatment $[n=92]$ and 0.92 at follow-up $[n=64])$. Compared to other Dutch-validated PROMs, our Cronbach's $\alpha$ for the OSIS was higher than that of the SST (0.78) and lower than that of the OSS $(0.92)[17,22]$.

Considering the content of the questions, it is clear that the OSIS measures several constructs, such as pain, physical-, social-, and role functioning, frequency of dislocation and worries.

The reliability was addressed with a test-retest sample in 99 patients with a mean interval of 13 days (5-30) and showed an ICC of 0.88 . This was lower than the 0.97 that Dawson et al. described after a 24-h interval in 34 patients; nevertheless, 0.88 is considered a very good ICC.

To our knowledge, the measurement error (SDC) of the OSIS has not been reported previously. Our SDC value showed that, to determine a treatment effect, one 
Table 3 Test-retest reliability (ICC), standard error of measurement (SEM) and smallest detectable change (SDC) for the OSIS

\begin{tabular}{lllllll}
\hline & Baseline & Re-test & Change & SEM & SDC & ICC (95 \% Cl) \\
& Mean (SD) & Mean (SD) & Mean (SD) & & & \\
\hline New scoring system & $27.2(9.3)$ & $27.6(9.7)$ & $-0.4(4.8)$ & 3.3 & 9.0 & $0.87(0.82-0.91)$ \\
\hline
\end{tabular}

Scores are expressed according to the new scoring system. This analysis included 99 patients that completed the baseline and retest evaluations

must find a difference of at least 9 points between two scores from an individual patient to ensure that the difference was not due to measurement error [48].

To assess the construct validity, Dawson et al. calculated correlations with the Rowe and Constant scores. However, the Rowe and Constant scores are not PROMs but observer-based measurement instruments. Moreover, the Constant score is not considered applicable to shoulder instability $[49,50]$. Therefore, the construct validity was assessed by calculating correlations with the WOSI, the SST, the OSS, the DASH and the SF-36 subscales. With $80 \%$ of the results in accordance with our hypotheses, the construct validity was considered good. The highest correlation (0.82) was observed between the two instabilityspecific PROMs (OSIS and the WOSI).

A high correlation was observed with the DASH (0.79), which addresses daily activities more specifically than the OSIS. However, many questions overlapped such as 'putting on a pullover sweater' (DASH) and 'during the last three months, have you had any trouble (or worry) dressing, because of your shoulder?' (OSIS). This similarity might explain the high correlation between the two instruments.

The OSIS was more closely correlated with the SF-36 subscales 'pain' (0.78) and 'role physical' (0.69) than with the subscale 'physical function' (0.65). These correlations were comparable to those described by Dawson et al. This may indicate that, in addition to physical function,

Table 4 Observed correlations for testing the validity of the Dutch version of OSIS

\begin{tabular}{ll}
\hline & Observed correlations \\
\hline 1. OSIS and WOSI & 0.82 \\
2. OSIS and SST & 0.69 \\
3. OSIS and OSS & 0.76 \\
4. OSIS and DASH & 0.79 \\
5. OSIS and SF-36 subscales: & \\
Physical function & 0.65 \\
General health & 0.31 \\
Social function & 0.56 \\
Vitality & 0.39 \\
Mental health & 0.20 \\
Role emotional & 0.41 \\
Role functional & 0.69 \\
Bodily Pain & 0.78 \\
\hline
\end{tabular}

the OSIS measures aspects of pain and role limitations due to physical problems.

In previous studies, floor and ceiling effects were not addressed. In this study, no patient had the maximum or minimum score. The estimation of the smallest detectable change indicated that the baseline patient scores should ideally be at least 9 points different from the extremes. That margin would enable detection of improvements and deteriorations that are distinct from measurement errors at follow-up. At most, $12 \%$ of patients scored within the SDC-margin; thus, these scores were less than the commonly used cut off of $15 \%$ [47].

A strong aspect of this study was the large size of our patient population without missing values.

Conversely, an unavoidable limitation of this study was the total number of questions posed to the patients. Completing six questionnaires at once requires considerable time and concentration, and patients might have digressed or lost focus. Also, although web-based versions have many advantages over paper versions such as an increased follow-up ratio and prevention of missing data, validation of digital formats should still be performed. Here, the results are expressed according to the new scoring system. It is important to be aware of the changed scoring system, and we recommend that future studies should specify the scoring system used.

Finally, for future studies, it would be very interesting to determine responsiveness and the minimal important change (MIC) of the OSIS. This information can be used to determine whether the observed change is important to the patient and to calculate the percentage of patients that report changes greater than the MIC (responders) in each arm of a trial. Then, the percentage of responders can be compared between groups [51].

\section{Conclusion}

This study found that the Dutch version of the OSIS was a reliable outcome measure in patients with shoulder

Table 5 Floor and ceiling effects of the OSIS scoring system

\begin{tabular}{|c|c|c|c|c|c|c|c|}
\hline \multirow[t]{2}{*}{$\begin{array}{l}\text { Scoring } \\
\text { system }\end{array}$} & \multirow[t]{2}{*}{$\begin{array}{l}\text { Absolute } \\
\text { floor }\end{array}$} & \multirow[t]{2}{*}{$\begin{array}{l}\text { Absolute } \\
\text { ceiling }\end{array}$} & \multirow[t]{2}{*}{ SDC } & \multicolumn{2}{|c|}{$\begin{array}{l}\text { SDC-range } \\
\text { from }\end{array}$} & \multicolumn{2}{|c|}{$\begin{array}{l}\% \text { of patients } \\
\text { scoring within } \\
\text { SDC range }\end{array}$} \\
\hline & & & & Floor & Ceiling & Floor & Ceiling \\
\hline New $(48-0)^{a}$ & No & No & 9.0 & $48-39$ & 9-0 & $12 \%$ & $4 \%$ \\
\hline
\end{tabular}


instability, with a Cronbach's $\alpha$ of 0.87 and an ICC of 0.87 . In addition, the construct validity was considered good. Comprising 12 questions, the OSIS is user-friendly and can be easily administered. Furthermore, in the absence of floor or ceiling effects, it is a valuable PROM in clinical practice. Patients need to change at least 9 points to ensure that the difference is not due to measurement error.

The Dutch version of the OSIS can be acquired by its managing institution, Isis Outcomes, Isis Innovation Ltd, holding its copyright (http://isis-innovation.com/outcome-measures/oxford-shoulder-instability-score-osis/).

\section{Additional file}

Additional file 1: Appendix 1. Confirmatory factor analysis to assess internal consistency. (DOCX $19 \mathrm{~kb}$ )

\section{Competing interests}

The authors declare that they have no competing interests.

\section{Authors' contributions}

All authors have made substantial contributions to conception and design, or acquisition of data, or analysis and interpretation of data; have been involved in drafting the manuscript or revising it critically for important intellectual content; have given final approval of the version to be published; and agree to be accountable for all aspects of the work in ensuring that questions related to the accuracy or integrity of any part of the work are appropriately investigated and resolved. JvdL is the principal investigator for this study. He carried out the final inclusion of patients and data collection, and he is the author of the first and consecutive drafts of the manuscript. He is the corresponding author. DvK initiated the inclusion of patients and designed the study protocol. He contributed daily help in the analysis and obtained ethical approval for this study. LVB assisted significantly in the analysis and interpretation of the data. DvD supervised the inclusion of patients at the end of the study. He actively participated in the writing. CT designed the study protocol and kept an overview on the analysis, writing and completion of this study. WW was the initiator of this study and included a significant part of the patients; he supervised this study.

\section{Acknowledgements}

We thank Mr. R. Cohen for his help in the translation and Mrs. R. Pepping for her help in coordinating patients' affairs. We thank the Department of Orthopedic Surgery and Traumatology at the Waterlandziekenhuis, the Netherlands for their financial contribution to publish this study.

\section{Author details}

'Department of Orthopedic Surgery and Traumatology, Onze Lieve Vrouwe Gasthuis, Postbus 95500, 1090 HM Amsterdam, The Netherlands. ${ }^{2}$ Department of Orthopedic Surgery and Traumatology, Waterland Ziekenhuis, Purmerend, The Netherlands. ${ }^{3}$ Department of Epidemiology and Biostatistics and the EMGO Institute for Health and Care Research, VU Medical Center, Amsterdam, The Netherlands. ${ }^{4}$ Department of Orthopedic Surgery and Traumatology, De Lairesse Kliniek, Amsterdam, The Netherlands.

Received: 6 July 2015 Accepted: 2 September 2015

Published online: 17 September 2015

\section{References}

1. Leroux T, Wasserstein D, Veillette C, Khoshbin A, Henry P, Chahal J, et al. Epidemiology of primary anterior shoulder dislocation requiring closed reduction in Ontario, Canada. Am J Sports Med. 2014:42:442-50.

2. Liavaag S, Svenningsen S, Reikeras O, Enger M, Fjalestad T, Pripp AH, et al. The epidemiology of shoulder dislocations in Oslo. Scand J Med Sci Sports. 2011;21:e334-40
3. Zacchilli MA, Owens BD. Epidemiology of shoulder dislocations presenting to emergency departments in the United States. J Bone Joint Surg Am. 2010;92:542-9.

4. Janse AJ, Gemke RJ, Uiterwaal CS, van dTI, Kimpen JL, Sinnema G. Quality of life: patients and doctors don't always agree: a meta-analysis. J Clin Epidemiol. 2004;57:653-61.

5. Wright RW, Baumgarten KM. Shoulder outcomes measures. J Am Acad Orthop Surg. 2010;18:436-44.

6. Irrgang JJ, Lubowitz JH. Measuring arthroscopic outcome. Arthroscopy. 2008;24:718-22.

7. Poolman RW, Swiontkowski MF, Fairbank JC, Schemitsch EH, Sprague S, de Vet HC. Outcome instruments: rationale for their use. J Bone Joint Surg Am. 2009;91 Suppl 3:41-9.

8. Dawson J, Fitzpatrick R, Carr A. The assessment of shoulder instability. The development and validation of a questionnaire. J Bone Joint Surg Br. 1999:81:420-6.

9. Steffen $V$, Hertel R. Rim reconstruction with autogenous iliac crest for anterior glenoid deficiency: forty-three instability cases followed for 5-19 years. J Shoulder Elbow Surg. 2013;22:550-9.

10. Tan CK, Guisasola I, Machani B, Kemp G, Sinopidis C, Brownson P, et al. Arthroscopic stabilization of the shoulder: a prospective randomized study of absorbable versus nonabsorbable suture anchors. Arthroscopy. 2006:22:716-20.

11. van der Linde JA, van Kampen DA, Terwee CB, Dijksman LM, Kleinjan G, Willems WJ. Long-term results after arthroscopic shoulder stabilization using suture anchors: an 8- to 10-year follow-up. Am J Sports Med. 2011;39:2396-403.

12. Beaton DE, Bombardier C, Guillemin F, Ferraz MB. Guidelines for the process of cross-cultural adaptation of self-report measures. Spine (Phila Pa 1976). 2000;15;25:3186-91.

13. Guillemin F, Bombardier C, Beaton D. Cross-cultural adaptation of health-related quality of life measures: literature review and proposed guidelines. J Clin Epidemiol. 1993;46:1417-32.

14. Wild D, Grove A, Martin M, Eremenco S, McElroy S, Verjee-Lorenz A, et al. Principles of good practice for the translation and cultural adaptation process for patient-reported outcomes (PRO) measures: report of the ISPOR task force for translation and cultural adaptation. Value Health. 2005;8:94-104.

15. Mokkink LB, Terwee CB, Patrick DL, Alonso J, Stratford PW, Knol DL, et al. The COSMIN checklist for assessing the methodological quality of studies on measurement properties of health status measurement instruments: an international Delphi study. Qual Life Res. 2010;19:539-49.

16. Terwee CB, Mokkink LB, Knol DL, Ostelo RW, Bouter LM, de Vet HC. Rating the methodological quality in systematic reviews of studies on measurement properties: a scoring system for the COSMIN checklist. Qual Life Res. 2012;21:651-7.

17. van Kampen DA, van Beers LW, Scholtes VA, Terwee CB, Willems WJ. Validation of the Dutch version of the simple shoulder test. J Shoulder Elbow Surg. 2012;21:808-14.

18. de Vet HC, Terwee CB, Mokkink LB, Knol DL. Design of simple reliability studies. Measurement in medicine. New York: Cambridge University Press; 2011. p. 125.

19. Dawson J, Rogers K, Fitzpatrick R, Carr A. The Oxford shoulder score revisited. Arch Orthop Trauma Surg. 2009;129:119-23.

20. van der Linde JA, Willems WJ, van Kampen DA, van Beers LW, van Deurzen DF, Terwee CB. Measurement properties of the Western Ontario Shoulder Instability index in Dutch patients with shoulder instability. BMC Musculoskelet Disord. 2014;15:211.

21. Godfrey J, Hamman R, Lowenstein S, Briggs K, Kocher M. Reliability, validity, and responsiveness of the simple shoulder test: psychometric properties by age and injury type. J Shoulder Elbow Surg. 2007;16:260-7.

22. Berendes T, Pilot $P$, Willems J, Verburg H, te SR. Validation of the Dutch version of the Oxford Shoulder Score. J Shoulder Elbow Surg. 2010;19:829-36.

23. Veehof MM, Sleegers EJ, van Veldhoven $\mathrm{NH}$, Schuurman $\mathrm{AH}$, van Meeteren NL. Psychometric qualities of the Dutch language version of the Disabilities of the Arm, Shoulder, and Hand questionnaire (DASH-DLV). J Hand Ther. 2002;15:347-54.

24. Kirkley A, Griffin S, McLintock $\mathrm{H}, \mathrm{Ng}$ L. The development and evaluation of a disease-specific quality of life measurement tool for shoulder instability. The Western Ontario Shoulder Instability Index (WOSI). Am J Sports Med. 1998;26:764-72.

25. Kirkley A, Griffin S, Dainty K. Scoring systems for the functional assessment of the shoulder. Arthroscopy. 2003;19:1109-20. 
26. Cacchio A, Paoloni M, Griffin SH, Rosa F, Properzi G, Padua L, et al. Cross-cultural adaptation and measurement properties of an Italian version of the Western Ontario Shoulder Instability Index (WOSI). J Orthop Sports Phys Ther. 2012:42:559-67.

27. Hatta T, Shinozaki N, Omi R, Sano H, Yamamoto N, Ando A, et al. Reliability and validity of the Western Ontario Shoulder Instability Index (WOSI) in the Japanese population. J Orthop Sci. 2011;16:732-6.

28. Salomonsson B, Ahlstrom S, Dalen N, Lillkrona U. The Western Ontario Shoulder Instability Index (WOSI): validity, reliability, and responsiveness retested with a Swedish translation. Acta Orthop. 2009:80:233-8.

29. Hofstaetter JG, Hanslik-Schnabel B, Hofstaetter SG, Wurnig C, Huber W. Cross-cultural adaptation and validation of the German version of the Western Ontario Shoulder Instability index. Arch Orthop Trauma Surg. 2010;130:787-96

30. Drerup S, Angst F, Griffin S, Flury MP, Simmen BR, Goldhahn J. Western Ontario shoulder instability index (WOSI): translation and cross-cultural adaptation for use by German speakers. Orthopade. 2010;39:711-8.

31. Lippitt SBHDIMFI. A practical tool for evaluating function: the Simple Shoulder Test. In: Matsen III FA, Fu FH, Hawkins RJ, editors. The shoulder: a balance of mobility and stability. Rosemont (IL): American Academy of Orthopaedic Surgeons; 1993.

32. Dawson J, Fitzpatrick R, Carr A. Questionnaire on the perceptions of patients about shoulder surgery. J Bone Joint Surg Br. 1996;78:593-600.

33. Frich $\mathrm{LH}$, Noergaard PM, Brorson S. Validation of the Danish version of Oxford Shoulder Score. Dan Med Bull. 2011;58:A4335

34. Huber W, Hofstaetter JG, Hanslik-Schnabel B, Posch M, Wurnig C. The German version of the Oxford Shoulder Score-cross-cultural adaptation and validation. Arch Orthop Trauma Surg. 2004;124:531-6.

35. Murena L, Vulcano E, D'Angelo F, Monti M, Cherubino P. Italian cross-cultural adaptation and validation of the Oxford Shoulder Score. J Shoulder Elbow Surg. 2010;19:335-41.

36. Roh YH, Noh JH, Kim W, Oh JH, Gong HS, Baek GH. Cross-cultural adaptation and validation of the Korean version of the Oxford shoulder score. Arch Orthop Trauma Surg. 2012;132:93-9.

37. Tugay U, Tugay N, Gelecek N, Ozkan M. Oxford Shoulder Score: cross-cultural adaptation and validation of the Turkish version. Arch Orthop Trauma Surg. 2011;131:687-94

38. Hudak PL, Amadio PC, Bombardier C. Development of an upper extremity outcome measure: the DASH (disabilities of the arm, shoulder and hand) [corrected]. The Upper Extremity Collaborative Group (UECG). Am J Ind Med. 1996;29:602-8.

39. Beaton DE, Katz JN, Fossel AH, Wright JG, Tarasuk V, Bombardier C. Measuring the whole or the parts? Validity, reliability, and responsiveness of the Disabilities of the Arm, Shoulder and Hand outcome measure in different regions of the upper extremity. J Hand Ther. 2001;14:128-46.

40. Desai AS, Dramis A, Hearnden AJ. Critical appraisal of subjective outcome measures used in the assessment of shoulder disability. Ann R Coll Surg Engl. 2010;92:9-13.

41. Garratt A, Schmidt L, Mackintosh A, Fitzpatrick R. Quality of life measurement: bibliographic study of patient assessed health outcome measures. BMJ. 2002;15;324:1417.

42. Salaffi F, De Angelis R, Stancati A, Grassi W. Health-related quality of life in multiple musculoskeletal conditions: a cross-sectional population based epidemiological study. II. The MAPPING study. Clin Exp Rheumatol. 2005:23:829-39.

43. Gartsman GM, Brinker MR, Khan M, Karahan M. Self-assessment of general health status in patients with five common shoulder conditions. J Shoulder Elbow Surg. 1998;7:228-37.

44. Ostor AJ, Richards CA, Prevost AT, Speed CA, Hazleman BL. Diagnosis and relation to general health of shoulder disorders presenting to primary care. Rheumatology (Oxford). 2005:44:800-5.

45. Snyder CF, Aaronson NK, Choucair AK, Elliott TE, Greenhalgh J, Halyard MY, et al. Implementing patient-reported outcomes assessment in clinical practice: a review of the options and considerations. Qual Life Res. 2012;21:1305-14.

46. Terwee CB, Bot SD, de Boer MR, van der Windt DA, Knol DL, Dekker J, et al, Quality criteria were proposed for measurement properties of health status questionnaires. J Clin Epidemiol. 2007;60:34-42.
47. McHorney CA, Tarlov AR. Individual-patient monitoring in clinical practice: are available health status surveys adequate? Qual Life Res. 1995;4:293-307.

48. de Vet $\mathrm{HC}$, Terwee $C B, \mathrm{Knol} \mathrm{DL}$, Bouter $\mathrm{LM}$. When to use agreement versus reliability measures. J Clin Epidemiol. 2006;59:1033-9.

49. Jensen KU, Bongaerts $G$, Bruhn R, Schneider S. Not all Rowe scores are the same! Which Rowe score do you use? J Shoulder Elbow Surg. 2009;18:511-4.

50. Lillkrona U. How should we use the Constant Score?-A commentary. J Shoulder Elbow Surg. 2008;17:362-3.

51. Schunemann HJ, AkI EA, Guyatt GH. Interpreting the results of patient reported outcome measures in clinical trials: the clinician's perspective. Health Qual Life Outcomes. 2006;4:62

\section{Submit your next manuscript to BioMed Central and take full advantage of:}

- Convenient online submission

- Thorough peer review

- No space constraints or color figure charges

- Immediate publication on acceptance

- Inclusion in PubMed, CAS, Scopus and Google Scholar

- Research which is freely available for redistribution 